\title{
Communication \\ Efficient Deep-Blue Electroluminescence Employing Heptazine-Based Thermally Activated Delayed Fluorescence
}

\author{
Jie Li ${ }^{1}{ }^{\circledR}$, Jincheng Zhang ${ }^{1}$, Heqi Gong ${ }^{1}$, Li Tao ${ }^{1}$, Yanqing Wang ${ }^{2}$ and Qiang Guo ${ }^{1, *}$ \\ 1 College of Optoelectronic Engineering, Chengdu University of Information Technology, \\ Chengdu 610225, China; lijie@cuit.edu.cn (J.L.); 3201105004@stu.cuit.edu.cn (J.Z.); \\ 3201105022@stu.cuit.edu.cn (H.G.); taoli@cuit.edu.cn (L.T.) \\ 2 College of Polymer Science and Engineering, Sichuan University, Chengdu 610065, China; \\ yanqingwang@scu.edu.cn \\ * Correspondence: qiangguo@cuit.edu.cn
}

Citation: Li, J.; Zhang, J.; Gong, H.; Tao, L.; Wang, Y.; Guo, Q. Efficient Deep-Blue Electroluminescence Employing Heptazine-Based Thermally Activated Delayed Fluorescence. Photonics 2021, 8, 293. https://doi.org/10.3390/ photonics 8080293

Received: 30 June 2021

Accepted: 21 July 2021

Published: 22 July 2021

Publisher's Note: MDPI stays neutral with regard to jurisdictional claims in published maps and institutional affiliations.

Copyright: (c) 2021 by the authors. Licensee MDPI, Basel, Switzerland. This article is an open access article distributed under the terms and conditions of the Creative Commons Attribution (CC BY) license (https:/ creativecommons.org/licenses/by/ $4.0 /)$

\begin{abstract}
We report an efficient deep-blue organic light-emitting diode (OLED) based on a heptazinebased thermally activated delayed fluorescent (TADF) emitter, 2,5,8-tris(diphenylamine)-tri-s-triazine (HAP-3DPA). The deep-blue-emitting compound, HAP-3DPA, was designed and synthesized by combining the relatively rigid electron-accepting heptazine core with three electron-donating diphenylamine units. Due to the rigid molecular structure and intramolecular charge transfer characteristics, HAP-3DPA in solid state presented a high photoluminescence quantum yield of $67.0 \%$ and obvious TADF nature with a short delayed fluorescent lifetime of $1.1 \mu \mathrm{s}$. Most importantly, an OLED incorporating HAP-3DPA exhibited deep-blue emission with Commission Internationale de l'Eclairage (CIE) coordinates of $(0.16,0.13)$, a peak luminance of $10,523 \mathrm{~cd} / \mathrm{m}^{-2}$, and a rather high external quantum efficiency of $12.5 \%$ without any light out-coupling enhancement. This finding not only reports an efficient deep-blue TADF molecule, but also presents a feasible pathway to construct high-performance deep-blue emitters and devices based on the heptazine skeleton.
\end{abstract}

Keywords: organic light-emitting diode; thermally activated delayed fluorescence; heptazine; deep blue emitter; electroluminescence

\section{Introduction}

Considerable progress in organic light-emitting diodes (OLEDs) based on thermally activated delayed fluorescence (TADF) has triggered intensive effort to develop highperformance pure organic electroluminescent (EL) materials over the past decade [1-5]. As the third generation of organic light-emitting materials in comparison with traditional fluorescent and phosphorescent materials, TADF emitters can harvest both singlet and triplet excitons without the use of noble metals, which are consequently considered as the promising option for next-generation OLEDs with numerous features, such as high efficiency, metal-free, diverse molecular design, and low cost [6-8]. To get full-color displays or white-light OLEDs, the utilization of blue emitters is indispensable, and many kinds of molecular skeletons (e.g., boron-containing, diphenylsulfone-based, triazine-pyrimidinebased) have been developed [9]. To date, a large number of blue TADF emitters have been developed, whereas most of them belong to the sky-blue region [10-17]. Hence, highly efficient deep-blue TADF emitters are still urgently required.

An effective separation of electron densities of the highest occupied molecular orbital (HOMO) and the lowest unoccupied molecular orbital (LUMO) in a single molecule is essential for the realization of a small energy gap $\left(\Delta E_{\mathrm{ST}}\right)$ between the lowest excited singlet state $\left(S_{1}\right)$ and the lowest excited triplet state $\left(T_{1}\right)$ [18]. In order to obtain a small $\Delta E_{\mathrm{ST}}$ and efficient TADF emitters, molecules featuring electron donor-acceptor strcutures are very popular and effective. Thereinto, the heptazine core, which has a considerably planar and rigid heterocyclic system of six $\mathrm{C}=\mathrm{N}$ bonds surrounding a central $\mathrm{sp}^{2}$-hybridised $\mathrm{N}$-atom, 
is an ideal strong electron acceptor [19-22]. To the best of our knowledge, several highly efficient heptazine-based red and green TADF emitters have been reported [22-25], while there are no published heptazine-based blue or deep-blue TADF emitters.

In this study, we designed and synthesized an efficient heptazine-based deep-blue TADF emitter, 2,5,8-tris(diphenylamine)-tri-s-triazine (HAP-3DPA), by integrating three electron-donating diphenylamine units into the strong electron-accepting heptazine core. The photoluminescence (PL) and electroluminescence (EL) properties of HAP-3DPA were systematically investigated. On account of the pretty rigid molecular geometry and charge transfer (CT) characteristics, HAP-3DPA in solid film exhibited high thermally stability, a high photoluminescence quantum yield (PLQY) of $67 \%$, and apparent TADF nature along with a short delay emission lifetime of $1.1 \mu \mathrm{s}$. More importantly, an HAP-3DPA-based OLED showed deep-blue emission with Commission Internationale de l'Eclairage (CIE) coordinates of $(0.16,0.13)$ and a reasonably high external quantum efficiency (EQE) of $12.5 \%$, together with a peak luminance of $10,523 \mathrm{~cd} / \mathrm{m}^{-2}$ without any light out-coupling enhancement.

\section{Materials and Methods}

\subsection{Synthesis of 2,5,8-Tris(Diphenylamine)-Tri-s-Triazine (HAP-3DPA)}

Diphenylamine and extra dry solvents (xylene stored with molecular sieves) were obtained from commercial suppliers and used without further purification. A flame-dried Schlenk tube with a magnetic stir bar was charged with mixture of cyameluric chloride $(1.09 \mathrm{mmol}, 300 \mathrm{mg})$, diphenylamine $(17.7 \mathrm{mmol}, 3.3 \mathrm{~g})$, and dry xylene $(20 \mathrm{~mL})$ under a $\mathrm{N}_{2}$ atmosphere. The resulting mixture was heated at $180^{\circ} \mathrm{C}$ for $24 \mathrm{~h}$. After cooling to room temperature, the solvent was removed by vacuum distillation. The residue was purified by column chromatography on silica gel and recrystallized from ethyl acetate/petroleum ether mixtures to provide the desired product as white solid $(577 \mathrm{mg}, 78 \%) .{ }^{1} \mathrm{H}$ NMR $(400 \mathrm{MHz}$, DMSO- $\left.d_{6}\right): \delta=7.32\left(\mathrm{td}, J_{1}=8.0 \mathrm{~Hz}, J_{2}=2.0 \mathrm{~Hz}, 12 \mathrm{H}\right), 7.17-7.24(\mathrm{~m}, 18 \mathrm{H}) \mathrm{ppm} .{ }^{13} \mathrm{C} \mathrm{NMR}$ $\left(100 \mathrm{MHz}, \mathrm{DMSO}-d_{6}\right): \delta=164.2,155.9,143.1,129.2,128.1,126.9 \mathrm{ppm}$. High-resolution mass spectrometry (HRMS) $\left(\right.$ ESI $^{+}$): calcd. for $\mathrm{C}_{42} \mathrm{H}_{30} \mathrm{~N}_{10}[\mathrm{M}+\mathrm{H}]^{+}$675.2733, found 675.2732. Elemental anal. calcd. for $\mathrm{C}_{42} \mathrm{H}_{30} \mathrm{~N}_{10}$ (\%): $\mathrm{C}, 74.76 ; \mathrm{H}, 4.48 ; \mathrm{N}, 20.76$; found: $\mathrm{C} 74.72,4.47$, N 20.80 .

\subsection{OLED Fabrication and Measurement}

The OLED was fabricated by vacuum thermal evaporation under a pressure lower than $5 \times 10^{-4} \mathrm{~Pa}$. An 150-nm-thick indium-tin-oxide (ITO) precoated glass substrate was used as the anode. Prior to the deposition of the organic layers and cathode, the substrate was firstly cleaned with ultra-purified water, acetone, and isopropyl alcohol (IPA) in sequence, then treated with UV-ozone for $15 \mathrm{~min}$, and finally transferred to a vacuum thermal deposition system. The intersection of ITO and the metal electrodes gave an active device area of $4 \mathrm{~mm}^{2}$. The OLED device was characterized under atmospheric conditions without any encapsulation or light out-coupling enhancement. The EL spetrum, EQE, and current density-voltage-luminance $(J-V-L)$ characteristics of the OLED were recorded and measured with an Agilent E5273A semiconductor parameter analyzer and a Newport 1930C optical power meter. EL spectra were recorded using an Ocean Optics USB2000 multi-channel spectrometer.

\section{Results and Discussion}

As depicted in Scheme 1, HAP-3DPA was synthesized by cyameluric chloride and diphenylamine in a good yield of $78 \%$. Thereinto, cyameluric chloride is the key intermediate and was prepared according to the literature [25]. The target compound was characterized and confirmed via ${ }^{1} \mathrm{H}$ and ${ }^{13} \mathrm{C}$ NMR spectroscopy (Figures S1 and S2 in Supplementary Materials), and HRMS. 


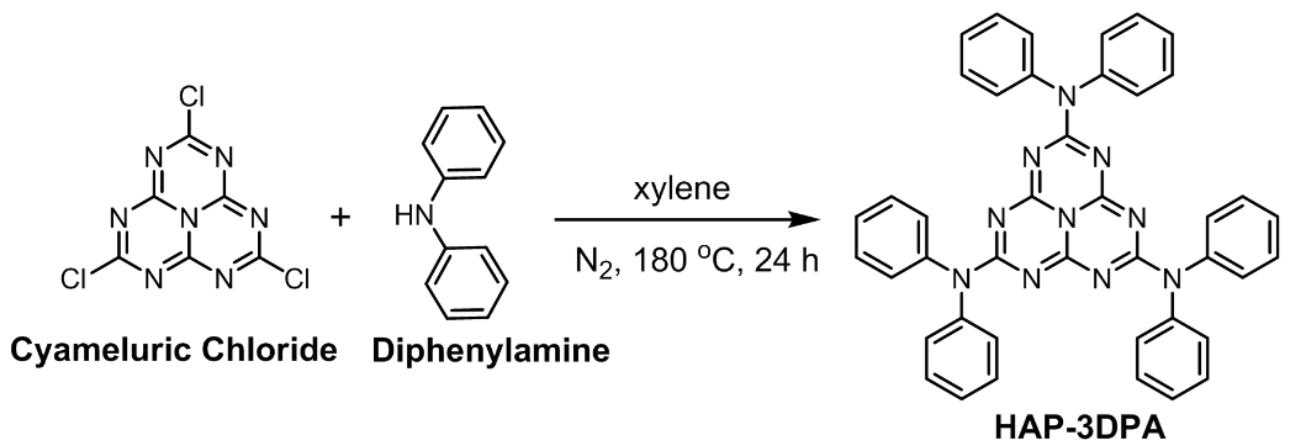

Scheme 1. Synthetic route of HAP-3DPA.

Quantum chemical calculations of HAP-3DPA were carried out based on density functional theory (DFT) and time-dependent DFT (TD-DFT) to predict the molecular configuration, electron cloud density distribution, and energy levels. As depicted in Figure 1 and Figure S3, the HOMO and LUMO are mainly distributed over the diphenylamine units and the heptazine core, respectively, which is in accordance with the electron-donating feature of DPA and electron-accepting character of heptazine core. Accordingly, the small overlap between the HOMO and LUMO leads to a small $\Delta E_{\mathrm{ST}}$ of $0.23 \mathrm{eV}$, which is beneficial to the realization of the TADF process. Interestingly, as compared to the previously reported highperformance red-emitting heptazine derivative, 4,4,4"-(1,3,3a $\mathrm{a}^{1}, 4,6,7,9$-heptaazaphenalene2,5,8-triyl)tris(N,N-bis(4-(tert-butyl)phenyl)aniline) (HAP-3TPA), which has a similar $\Delta E_{\mathrm{ST}}$ of $0.27 \mathrm{eV}$ and a small energy band gap between HOMO and LUMO $\left(E_{\mathrm{g}}\right)$ of $2.76 \mathrm{eV}$ (Figures S4 and S5), HAP-3DPA possesses a much larger $E_{\mathrm{g}}$ of $4.29 \mathrm{eV}$ and a rather higher $\mathrm{S}_{1}$ energy level of $3.53 \mathrm{eV}$, indicating the significant importance of subtle structural change of electron-donating moieties on photophysical properties. Additionally, we found that the natural transition orbitals (NTOs) for $\mathrm{T}_{1}$ of HAP-3DPA have the intramolecular charge transfer (CT) character and are related to the $\pi \rightarrow \pi^{*}$ transitions from HOMO to LUMO (Figure S6), while the NTOs for $\mathrm{S}_{1}$ of HAP-3DPA (HOMO-3 to LUMO) are deriving from more localized $n \rightarrow \pi^{*}$ transitions involving lone-pair electrons of $N$ heteroatoms and $\pi$ antibonding molecular orbitals (Figure S7). Therefore, it could be anticipated that the different NTOs nature of $S_{1}$ and $T_{1}$ can facilitate the reverse intersystem crossing (RISC) process from ${ }^{3} \pi \pi^{*}$ to ${ }^{1} \mathrm{n} \pi^{*}$ state according to the El-Sayed rule [26].

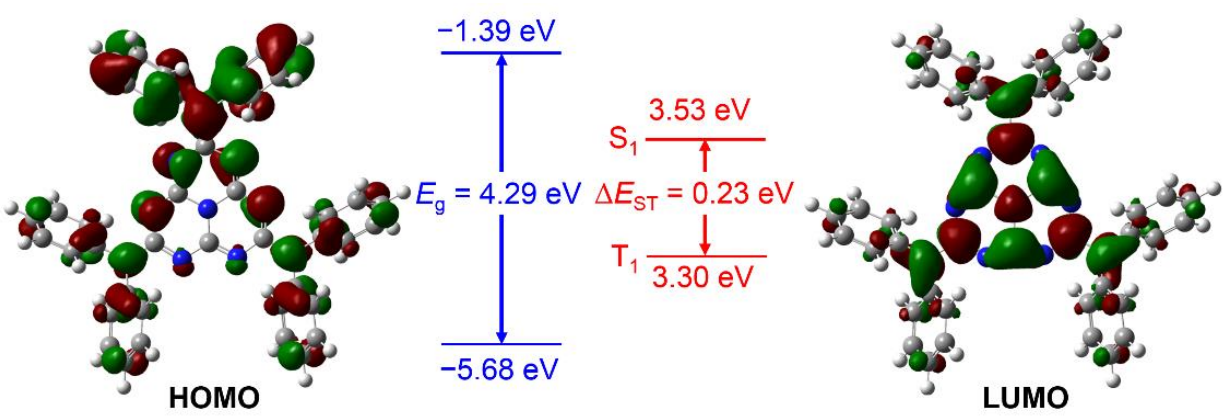

Figure 1. Frontier molecular orbital distributions and energy levels of the lowest excited singlet and triplet states of HAP-3DPA by theoretical calculations.

The thermal stability of HAP-3DPA was measured by thermo-gravimetric analysis (TGA) and differential scanning calorimetry (DSC). As shown in Figure $2 \mathrm{a}$ and Table 1, HAP3DPA showed a fairly high initial decomposition temperature ( $T_{\mathrm{d}}$ with a $5 \mathrm{wt} \%$ loss) of $448^{\circ} \mathrm{C}$ and a high glass-transition temperature $\left(T_{\mathrm{g}}\right)$ of $112{ }^{\circ} \mathrm{C}$, implying its excellent thermal stability and suitable for vacuum thermal evaporation process, which should be ascribed to the relatively rigid and planar molecular structure of HAP-3DPA. Furthermore, the HOMO energy level of HAP-3DPA was determined to be $-6.2 \mathrm{eV}$ by atmospheric ultraviolet photoelectron spectroscopy (Figure 2b). Moreover, HAP-3DPA in a neat film showed 
deep-blue emission with a peak wavelength $\left(\lambda_{\mathrm{em}}\right)$ of $420 \mathrm{~nm}$ (Figure $2 \mathrm{c}$ ). Consequently, the LUMO energy level of HAP-3DPA can be calculated to be $-2.9 \mathrm{eV}$ from the differences between the HOMO and optical $E_{\mathrm{g}}$. Meanwhile, the PLQY and transient PL decay of HAP-3DPA in a neat film were carried out. HAP-3DPA exhibited comparably high PLQYs of $34.7 \%$ and $39.2 \%$ in air and $\mathrm{N}_{2}$ atomosphere, respectively, which should be associated with the rather rigid molecular structure of HAP-3DPA in solid state. The relatively small difference $(4.5 \%)$ induced by oxygen should be ascribed to the TADF process considering the weak delayed emission component in Figure 2d.

(a)

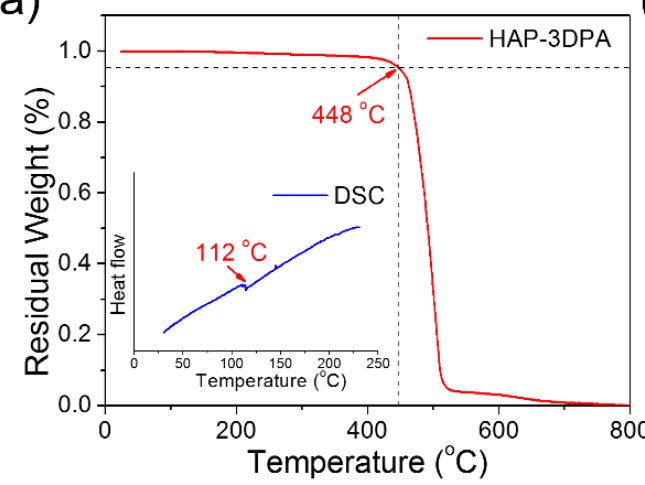

(c)

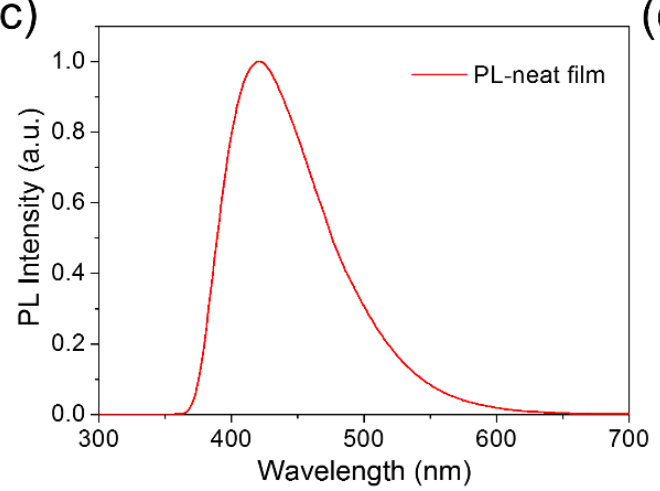

(b)

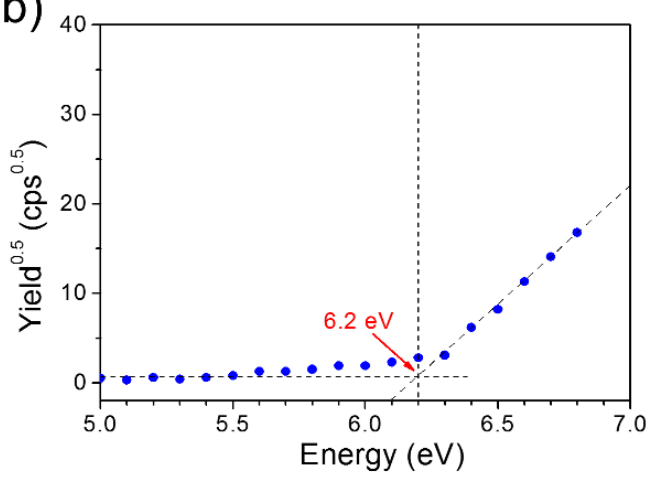

(d)

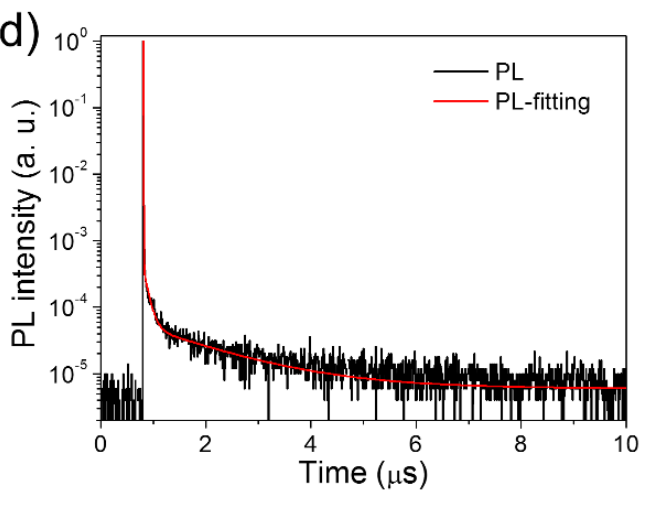

Figure 2. (a) The thermo-gravimetric analysis (TGA) and differential scanning calorimetry (DSC) curves of HAP-3DPA. (b) The HOMO energy level of HAP-3DPA determined by atmospheric ultraviolet photoelectron spectroscopy. (c) The PL spectrum of HAP-3DPA in a neat film. (d) The transient PL decay of HAP-3DPA in a neat film.

Table 1. Thermal and photophysical properties of HAP-3DPA.

\begin{tabular}{|c|c|c|c|c|c|c|}
\hline Compound & $T_{\mathrm{d}} / T_{\mathrm{g}}\left({ }^{\circ} \mathrm{C}\right)$ & $\begin{array}{l}\text { HOMO/ } \\
\text { LUMO }(\mathrm{eV})\end{array}$ & $\begin{array}{c}\lambda_{\text {em }}(\mathrm{nm}) \\
\text { Sol }^{\mathrm{a} / \text { Film }}{ }^{\mathrm{b}}\end{array}$ & $\begin{array}{c}\tau_{\mathrm{p}}(\mathrm{ns}) \\
\text { Sol }^{\mathrm{a} / \text { Film }} \mathrm{b}\end{array}$ & $\begin{array}{c}\tau_{\mathrm{d}}(\mu \mathrm{s}) \\
\text { Sol }^{\mathrm{a}} / \text { Film }^{\mathrm{b}}\end{array}$ & $\begin{array}{c}\text { PLQY } \\
\text { Sol }^{\text {a/Film }}{ }^{b}\end{array}$ \\
\hline HAP-3DPA & $448 / 112$ & $-6.2 /-2.9$ & $521 / 442$ & $4.0 / 3.0$ & $1.2 / 1.1$ & $16 \% / 67 \%$ \\
\hline
\end{tabular}

a sol: measured in oxygen-free toluene. ${ }^{\mathrm{b}}$ film: measured in a $6 \mathrm{wt} \%$ HAP-3DPA:DPEPO doped film.

The ultraviolet-visble (UV-vis) absorption and PL spectra of HAP-3DPA in diluted toluene at a concentration of $1 \times 10^{-4} \mathrm{~mol} \mathrm{~L}^{-1}$ are shown in Figure 3a. The strong absorption band centered at $313 \mathrm{~nm}$ can be assigned to $\pi \rightarrow \pi^{*}$ electronic transition with regard to the $\pi$ conjugated molecular system. Meanwhile, HAP-3DPA displayed green emissions in diluted toluene with $\lambda_{\mathrm{em}}=521 \mathrm{~nm}$ and a quite low PLQY of $16 \%$ (oxygenfree condition), indicating a large molecular geometry change of HAP-3DPA induced by toluene molecules in comparison to that in the neat film. To confirm the TADF nature, the transient PL decay of HAP-3DPA both in air-saturated and oxygen-free toluene were measured (Figure 3b). Delayed emission components could be clearly observed both in air-saturated and oxygen-free toluene although the PL intensities are weak. Obviously, as compared to the lifetime of delayed component $\left(\tau_{\mathrm{d}}=256 \mathrm{~ns}\right)$ in air-saturated condition, 
the $\tau_{\mathrm{d}}$ in oxygen-free condition was greatly enhanced to be $1.2 \mu \mathrm{s}$. Therefore, this oxygensensitive delayed component should be attributed to the TADF. Meanwhile, the lifetimes of prompt emission $\left(\tau_{\mathrm{p}}\right)$ are $4.0 \mathrm{~ns}$ both in air-saturated and oxygen-free toluene, showing no oxygen-dependence. To verify that the TADF occurs in HAP-3DPA in solid state, the photophysical properites of HAP-3DPA in a doped film were performed. As a famous host material for blue emitters, bis(2-(diphenylphosphino)phenyl) ether oxide (DPEPO) possesses a high $\mathrm{T}_{1}$ level over $3.0 \mathrm{eV}$ and was chosen as the host for HAP-3DPA [27], and a $6 \mathrm{wt} \%$ HAP-3DPA:DPEPO-doped film was fabricated and characterized. Herein, the concentration of $6 \mathrm{wt} \%$ was chosen based on the optimization of luminescence efficiencies at various concentrations (Table S1). The doped film showed deep-blue emission with $\lambda_{\mathrm{em}}=442 \mathrm{~nm}$ (Figure 3a), which is significantly blue shifted compared with that in toluene. Transient PL decay of the doped film was shown in Figure 3c and Figure S8. Similar to that in toluene, the doped film exhibited strong prompt and weak delayed components, with $\tau_{\mathrm{p}}=3.0 \mathrm{~ns}$ and $\tau_{\mathrm{d}}=1.1 \mu \mathrm{s}$. Such a short delayed fluorescence lifetime in solid state demonstrated that efficient RISC from $T_{1}$ to $S_{1}$ could occurr and efficient harvest of triplet exctons could be expected in EL performance. Excitingly, the doped film displayed a relativley high PLQY of $67 \%$, which is much higher than that of HAP-3DPA in a neat film or diluted toluene, suggesting efficient radiative transition of singlet excitons from $S_{1}$ to the ground state $\left(\mathrm{S}_{0}\right)$. The photophysical properties of HAP-3DPA in toluene and doped film are summarized in Table 1. To better elucidate the delayed emission, the prompt and delayed emission spectra of the $6 \mathrm{wt} \%$ HAP-3DPA:DPEPO doped film were characterized (Figure 3d). The well-overlapped PL spectra confirm that all photons were generated from the same excited state.
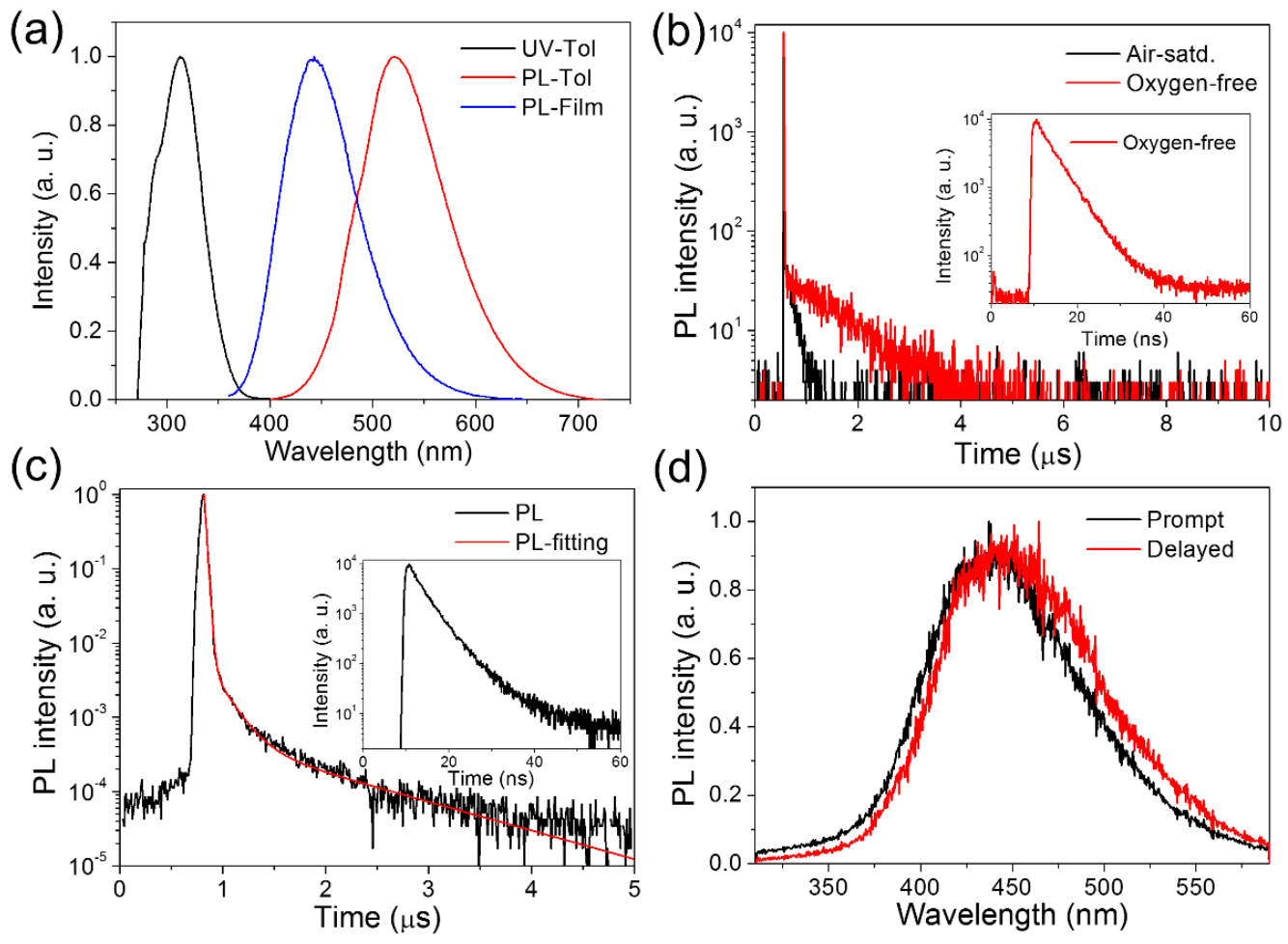

Figure 3. (a) The UV-vis and PL spectra of HAP-3DPA in toluene (Tol) and doped film (6 wt $\%$ HAP3DPA:DPEPO). (b) Transient PL decay of HAP-3DPA in air-saturated (Air-satd.) and oxygen-free toluene. Inset: Transient PL decay of HAP-3DPA in oxygen-free toluene with a time range of $60 \mathrm{~ns}$. (c) Transient PL decay of the $6 \mathrm{wt} \%$ HAP-3DPA:DPEPO-doped film. Inset: Transient PL decay in a time range of $60 \mathrm{~ns}$. (d) Prompt and delayed PL spectra of the $6 \mathrm{wt} \%$ HAP-3DPA:DPEPO-doped film.

To evaluate EL performance of HAP-3DPA, an OLED device incorporating an emitting layer of $6 \mathrm{wt} \%$ HAP-3DPA:DPEPO was fabricated. The solubility of HAP-3DPA is 
not enough to be applied into solution-processed OLED fabrication on the basis of high insolubility of heptazine core. Therefore, the OLED was prepared by vacuum thermal evaporation with a structure of ITO/ $\alpha$-NPD $(30 \mathrm{~nm}) / \mathrm{TCTA}(20 \mathrm{~nm}) / \mathrm{CzSi}(10 \mathrm{~nm}) / 6 \mathrm{wt} \%$ HAP-3DPA:DPEPO (20 nm)/DPEPO (10 nm)/TPBI (30 nm)/LiF (1 nm)/Al (Figure 4a), where $\alpha$-NPD, TCTA, CzSi and TPBI represent $N, N^{\prime}$-diphenyl- $N, N^{\prime}$-bis(1-naphthyl)-1,10biphenyl-4,4'-diamine, 4,4', $4^{\prime \prime}$-tris( $N$-carbazolyl)triphenylamine, 9-(4-tert-butylphenyl)3,6-bis(triphenylsilyl)-9H-carbazole, and 1,3,5-tris( $N$-phenylbenzimidazol-2-yl)benzene, respectively. The molecular structures of organic compounds employed in the device are shown in Figure S9. Here, the OLED architecture was optimized and chosen as compared to the EL performance with a simple three-layered structure (Figure S10 and Table S2). The EL spectra of this device measured at 1,10, and $100 \mathrm{~mA} \mathrm{~cm}^{-2}$ are well-overlapped with a maximum EL peak $\left(\lambda_{\mathrm{EL}}\right)$ of $440 \mathrm{~nm}$, and in good agreement with PL spectrum of the emitting layer (Figure $4 \mathrm{~b}$ ). Meanwhile, no detectable host emission was observed, suggesting excellent exciton confinement in the OLED. More importantly, the OLED showed deep-blue emission with CIE coordinates of $(0.16,0.13)$ and a rather high external quantum efficiency (EQE) of $12.5 \%$, a turn-on voltage $\left(V_{\text {on }}\right)$ of $4.1 \mathrm{~V}$, and a peak luminance $\left(L_{\max }\right)$ of $10,523 \mathrm{~cd} / \mathrm{m}^{-2}$ without any light out-coupling enhancement (Figure $4 \mathrm{c}, \mathrm{d}$, Figure S11, and Table 2). Moreover, comparably stable CIE coordinates in the deep-blue range were observed with applied voltage increasing (Figure S12). The excellent EL performance of this OLED is partly attributed to the well-balanced electron and hole fluxes into the emitting zone. Meanwhile, it should be ascribed to efficient up-conversion of triplet excitons from $\mathrm{T}_{1}$ to $\mathrm{S}_{1}$ through TADF process.

(a)

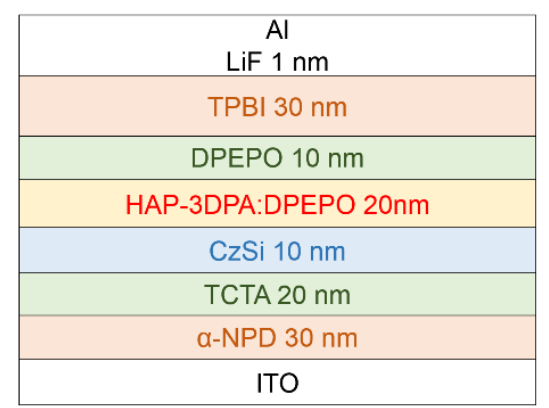

(c)

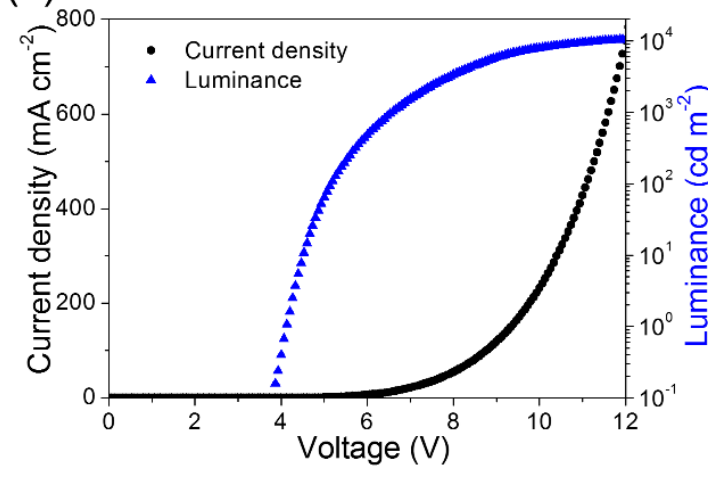

(b)

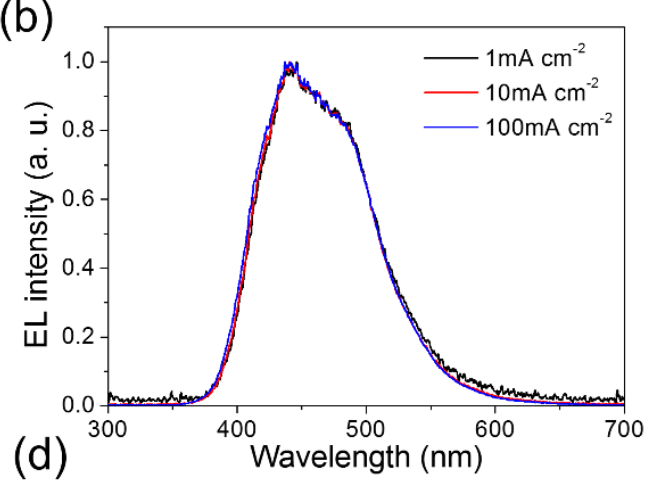

(d)

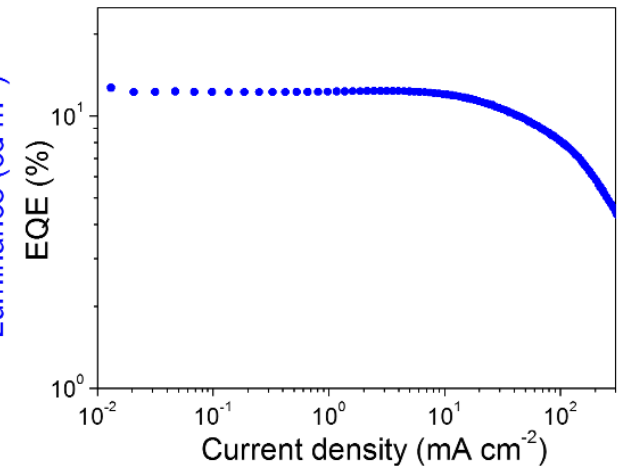

Figure 4. (a) The OLED structure. (b) The EL spectra at various current densities. (c) The current efficiency-voltage-luminance $(J-V-L)$ characteristics. (d) EQE as a function of current density.

Table 2. Summary of the OLED performance based on HAP-3DPA.

\begin{tabular}{cccccc}
\hline Emitter & $V_{\text {on }}(\mathbf{V})^{\mathbf{a}}$ & $\lambda_{\text {EL }}(\mathbf{n m})$ & $L_{\max }\left(\mathbf{c d} / \mathbf{m}^{-2}\right)$ & EQE (\%) & CIE (x, y) \\
\hline HAP-3DPA & 4.1 & 440 & 10,523 & 12.5 & $0.16,0.13$ \\
\hline
\end{tabular}

a Turn-on voltage at $1 \mathrm{~cd} / \mathrm{m}^{-2}$. 
Furthermore, it should be noted that there is a dramatic efficiency roll-off at high current densities for the OLED, $12.5 \%$ at $0.01 \mathrm{~mA} \mathrm{~cm}-2,12.3 \%$ at $1 \mathrm{~mA} \mathrm{~cm}{ }^{-2}, 10.0 \%$ at $10 \mathrm{~mA} \mathrm{~cm}^{-2}, 8.0 \%$ at $100 \mathrm{~mA} \mathrm{~cm}{ }^{-2}, 5.8 \%$ at $200 \mathrm{~mA} \mathrm{~cm}^{-2}$, and $4.5 \%$ at $300 \mathrm{~mA} \mathrm{~cm}^{-2}$ (Figure 4d). As shown in Figure S13, this effect can be predominantly ascribed to triplettriplet annihilation (TTA) on the basis of theoretical TTA fitting [28]. In view of the short delayed fluorescence lifetime $(1.1 \mu \mathrm{s})$ of HAP-3DPA, a long device operational lifetime could be expected and will be systematically evaluated later [29-32].

\section{Conclusions}

In summary, we designed, synthesized, and characterized an efficient heptazine-based deep-blue TADF emitter, HAP-3DPA, which has an electron-accepting heptazine core and three electron-donating diphenylamine units. Deep-blue-emitting HAP-3DPA in solid state presented good thermal stability, a high PLQY, and obvious TADF nature with a short delayed emission lifetime. Most importantly, an OLED containing HAP-3DPA showed deep-blue emission with CIE coordinates of $(0.16,0.13)$ and a rather high external quantum efficiency (EQE) of $12.5 \%$ and a peak luminance of $10,523 \mathrm{~cd} / \mathrm{m}^{-2}$ without any light outcoupling enhancement. This study does not merely provide a highly efficient deep-blue TADF emitter, but rather offers a feasible pathway to construct high-performance deep-blue light-emitting materials and devices based on heptazine derivatives.

Supplementary Materials: The following are available online at https:/ / www.mdpi.com/article/ 10.3390 / photonics8080293/s1, instrumentation; copies of ${ }^{1} \mathrm{H}$ and ${ }^{13} \mathrm{C}$ NMR spectra of HAP-3DPA (Figures S1 and S2); quantum chemical calculations (Figures S3-S7); photophysical characteristics (Tables S1 and S2, Figures S8-S13).

Author Contributions: Conceptualization, J.L. and Q.G.; methodology, J.Z. and H.G.; software, J.Z. and H.G.; validation, J.L. and Q.G.; formal analysis, J.L. and Q.G.; investigation, J.L. and Q.G.; resources, L.T. and Y.W.; data curation, L.T. and Y.W.; writing-original draft preparation, J.L.; writing-review and editing, Q.G.; visualization, J.L. and Q.G.; supervision, L.T. and Y.W.; project administration, J.L. and Q.G.; funding acquisition, J.L. and Q.G. All authors have read and agreed to the published version of the manuscript.

Funding: This research was funded by the National Natural Science Foundation of China (grant numbers: 61505015, 21801028, 11704050), Department of Science and Technology of Sichuan Province (grant numbers: 2019YJ0358, 2017FZ0085, 2020YFG0038, 2020YFH0104), Fundamental Research Funds for the Central Universities (grant number: YJ201952) and Department of Human Resources and Social Security of Sichuan Province (grant number: 2019Z226).

Institutional Review Board Statement: Not applicable.

Informed Consent Statement: Not applicable.

Data Availability Statement: The data presented in this study are available on request from the corresponding author.

Conflicts of Interest: The authors declare no conflict of interest.

\section{References}

1. Uoyama, H.; Goushi, K.; Shizu, K.; Nomura, H.; Adachi, C. Highly efficient organic light-emitting diodes from delayed fluorescence. Nature 2012, 492, 234-238. [CrossRef]

2. Goushi, K.; Yoshida, K.; Sato, K.; Adachi, C. Organic light-emitting diodes employing efficient reverse intersystem crossing for triplet-to-singlet state conversion. Nat. Photonics 2012, 6, 253-258. [CrossRef]

3. Konidena, R.K.; Lee, J.Y. Molecular design tactics for highly efficient thermally activated delayed fluorescence emitters for organic light emitting diodes. Chem. Rec. 2019, 19, 1499-1517. [CrossRef]

4. Cai, M.; Zhang, D.; Duan, L. High performance thermally activated delayed fluorescence sensitized organic light-emitting diodes. Chem. Rec. 2019, 19, 1611-1623. [CrossRef]

5. Kim, J.U.; Park, I.S.; Chan, C.Y.; Tanaka, M.; Tsuchiya, Y.; Nakanotani, H.; Adachi, C. Nanosecond-time-scale delayed fluorescence molecule for deep-blue oleds with small efficiency rolloff. Nat. Commun. 2020, 11, 1765. [CrossRef]

6. Kim, M.; Jeon, S.K.; Hwang, S.H.; Lee, S.S.; Yu, E.; Lee, J.Y. Highly efficient and color tunable thermally activated delayed fluorescent emitters using a "twin emitter" molecular design. Chem. Commun. 2016, 52, 339-342. [CrossRef] 
7. Lundberg, P.; Lindh, E.M.; Tang, S.; Edman, L. Toward efficient and metal-free emissive devices: A solution processed host guest light-emitting electrochemical cell featuring thermally activated delayed fluorescence. ACS Appl. Mater. Inter. 2017, 9, 28810-28816. [CrossRef]

8. Yin, X.; He, Y.; Wang, X.; Wu, Z.X.; Pang, E.B.; Xu, J.; Wang, J.A. Recent advances in thermally activated delayed fluorescent polymer-molecular designing strategies. Front. Chem. 2020, 8, 725. [CrossRef] [PubMed]

9. Bui, T.T.; Goubard, F.; Ibrahim-Ouali, M.; Gigmes, D.; Dumur, F. Recent advances on organic blue thermally activated delayed fluorescence (TADF) emitters for organic light-emitting diodes (oleds). Beilstein J. Org. Chem. 2018, 14, 282-308. [CrossRef]

10. Zhang, Q.S.; Li, J.; Shizu, K.; Huang, S.P.; Hirata, S.; Miyazaki, H.; Adachi, C. Design of efficient thermally activated delayed fluorescence materials for pure blue organic light emitting diodes. J. Am. Chem. Soc. 2012, 134, 14706-14709. [CrossRef]

11. Liu, M.; Seino, Y.; Chen, D.C.; Inomata, S.; Su, S.J.; Sasabe, H.; Kido, J. Blue thermally activated delayed fluorescence materials based on bis(phenylsulfonyl)benzene derivatives. Chem. Commun. 2015, 51, 16353-16356. [CrossRef]

12. Lee, S.Y.; Adachi, C.; Yasuda, T. High-efficiency blue organic light-emitting diodes based on thermally activated delayed fluorescence from phenoxaphosphine and phenoxathiin derivatives. Adv. Mater. 2016, 28, 4626-4631. [CrossRef]

13. Sun, J.W.; Baek, J.Y.; Kim, K.H.; Huh, J.S.; Kwon, S.K.; Kim, Y.H.; Kim, J.J. Azasiline-based thermally activated delayed fluorescence emitters for blue organic light emitting diodes. J. Mater. Chem. C 2017, 5, 1027-1032. [CrossRef]

14. He, Z.Z.; Cai, X.Y.; Wang, Z.H.; Li, Y.C.; Xu, Z.D.; Liu, K.K.; Chen, D.C.; Su, S.J. Sky-blue thermally activated delayed fluorescence material employing a diphenylethyne acceptor for organic light-emitting diodes. J. Mater. Chem. C 2018, 6, 36-42. [CrossRef]

15. Joo, C.W.; Huseynova, G.; Yifei, J.; Yoo, J.M.; Kim, Y.H.; Cho, N.S.; Lee, J.H.; Kim, Y.H.; Lee, J. Highly efficient solution-processed blue organic light-emitting diodes based on thermally activated delayed fluorescence emitters with spiroacridine donor. J. Ind. Eng. Chem. 2019, 78, 265-270. [CrossRef]

16. Zhang, Z.; Crovini, E.; dos Santos, P.L.; Naqvi, B.A.; Cordes, D.B.; Slawin, A.M.Z.; Sahay, P.; Brutting, W.; Samuel, I.D.W.; Brase, S.; et al. Efficient sky-blue organic light-emitting diodes using a highly horizontally oriented thermally activated delayed fluorescence emitter. Adv. Opt. Mater. 2020, 8, 2001354. [CrossRef]

17. Shen, Y.F.; Zhao, W.L.; Lu, H.Y.; Wang, Y.F.; Zhang, D.W.; Li, M.; Chen, C.F. Naphthyridine-based thermally activated delayed fluorescence emitters for highly efficient blue oleds. Dyes Pigm. 2020, 178, 108324. [CrossRef]

18. Endo, A.; Sato, K.; Yoshimura, K.; Kai, T.; Kawada, A.; Miyazaki, H.; Adachi, C. Efficient up-conversion of triplet excitons into a singlet state and its application for organic light emitting diodes. Appl. Phys. Lett. 2011, 98, 083302. [CrossRef]

19. Schwarzer, A.; Saplinova, T.; Kroke, E. Tri-s-triazines (s-heptazines)-from a "mystery molecule" to industrially relevant carbon nitride materials. Coord. Chem. Rev. 2013, 257, 2032-2062. [CrossRef]

20. Kumar, S.; Sharma, N.; Kailasam, K. Emergence of s-heptazines: From trichloro-s-heptazine building blocks to functional materials. J. Mater. Chem. A 2018, 6, 21719-21728. [CrossRef]

21. Audebert, P.; Kroke, E.; Posern, C.; Lee, S.H. State of the art in the preparation and properties of molecular monomeric s-heptazines: Syntheses, characteristics, and functional applications. Chem. Rev. 2021, 121, 2515-2544. [CrossRef] [PubMed]

22. Li, J.; Gong, H.; Zhang, J.; Zhou, S.; Tao, L.; Jiang, L.; Guo, Q. Enhanced electroluminescence based on a pi-conjugated heptazine derivative by exploiting thermally activated delayed fluorescence. Front. Chem. 2021, 9, 693813. [CrossRef]

23. Li, J.; Zhang, Q.S.; Nomura, H.; Miyazaki, H.; Adachi, C. Thermally activated delayed fluorescence from ${ }^{3} \mathrm{n} \pi^{*}$ to ${ }^{1} \mathrm{n} \pi^{*}$ upconversion and its application to organic light-emitting diodes. Appl. Phys. Lett. 2014, 105, 013301. [CrossRef]

24. Li, J.; Nomura, H.; Miyazaki, H.; Adachi, C. Highly efficient exciplex organic light-emitting diodes incorporating a heptazine derivative as an electron acceptor. Chem. Commun. 2014, 50, 6174-6176. [CrossRef]

25. Li, J.; Nakagawa, T.; MacDonald, J.; Zhang, Q.; Nomura, H.; Miyazaki, H.; Adachi, C. Highly efficient organic light-emitting diode based on a hidden thermally activated delayed fluorescence channel in a heptazine derivative. Adv. Mater. 2013, 25, 3319-3323 [CrossRef]

26. El-Sayed, M.A. Spin-orbit coupling and the radiationless processes in nitrogen heterocyclics. J. Chem. Phys. 1963, 38, 2834-2838. [CrossRef]

27. Zhang, Q.S.; Komino, T.; Huang, S.P.; Matsunami, S.; Goushi, K.; Adachi, C. Triplet exciton confinement in green organic light-emitting diodes containing luminescent charge-transfer cu(i) complexes. Adv. Funct. Mater. 2012, 22, 2327-2336. [CrossRef]

28. Adachi, C.; Baldo, M.A.; Forrest, S.R. Electroluminescence mechanisms in organic light emitting devices employing a europium chelate doped in a wide energy gap bipolar conducting host. J. Appl. Phys. 2000, 87, 8049-8055. [CrossRef]

29. Kothavale, S.; Chung, W.J.; Lee, J.Y. High efficiency and long lifetime orange-red thermally activated delayed fluorescent organic light emitting diodes by donor and acceptor engineering. J. Mater. Chem. C 2021, 9, 528-536. [CrossRef]

30. Kim, D.; Yoon, S.J.; Lee, K.H.; Lee, J.Y.; Hong, W.P. Starburst type benzofuroindolocarbazole donor for high efficiency and long lifetime in thermally activated delayed fluorescence emitters. Adv. Opt. Mater. 2021, 9, 2001432. [CrossRef]

31. Konidena, R.K.; Lee, K.H.; Lee, J.Y. Molecular design featuring carbazole-decorated 15h-diindolo[2,3-b:1',2',3'-lm]carbazole for improved efficiency and lifetime of thermally activated delayed fluorescence emitters. J. Mater. Chem. C 2020, 8, 2491-2499. [CrossRef]

32. Kim, J.H.; Lee, K.H.; Lee, J.Y. Design of thermally activated delayed fluorescent sensitizers for high efficiency over $20 \%$ and long lifetime in yellow fluorescent organic light-emitting diodes. J. Mater. Chem. C 2020, 8, 5265-5272. [CrossRef] 